\title{
Strategi Pengembangan Bisnis Dengan Metode Business Model Canvas
}

\author{
Hartatik*, Teguh Baroto \\ Teknik Industri, Fakultas Teknik, Universitas Muhammadiyah Malang \\ Jl. Raya Tlogomas 246, Malang, Jawa Timur 65144 Telp 0341551253 /Fax 0341460435 \\ *Surel: hartatik@gmail.com
}

\begin{abstract}
The company is required to continue to grow. This research uses Business Model Canvas method. Business Methods Canvas model is done with several stages of internal and external analysis using IFE and EFE matrix and SWOT Analysis. The next step is to weight using AHP method to get a strategy, then give variety with Canvas Business Model. The Canvas Business Model covers nine blocks, Customer Relationships, Key Partners, Value Propositions, Customer Segments, and cash flow, key resources (key resources), key activities (key activities) and cost structures (cost structures). The result of the research shows strategy with Business Model Canvas can effectively and efficiently in determining company strategy.
\end{abstract}

Keywords: IFE Matrix \& EFE, SWOT Analysis, Analytical Hirarchy Process (AHP), Business Model Canvas.

\begin{abstract}
Abstrak
Perusahaan saat ini dituntut untuk terus berkembang. Penelitian ini menggunakan metode Business Model Canvas. Metode Business Model Canvas dilakukan dengan beberapa tahapan yaitu analisa internal dan eksternal menggunakan matriks IFE dan EFE serta analisa SWOT. Tahapan berikutnya adalah melakukan pembobotan menggunakan metode AHP untuk mendapatkan prioritas strategi, selanjutnya memberikan usulan perbaikan dengan Business Model Canvas. Business Model Canvas meliputi sembilan blok, yaitu Customer Relationships (hubungan pelanggan), Key Partners (kemitraan utama), Value Propositions (proporsi nilai), Customer Segments (segmen pelanggan) dan Channel (saluran), revenue stream (arus pendapatan), key resources (sumber daya utama), key activities (aktivitas kunci) dan cost structure (struktur biaya). Hasil penelitian menunjukkan strategi dengan Business Model Canvas dapat secara efektif dan efisien dalam penentuan strategi perusahaan.
\end{abstract}

Kata Kunci: Matriks IFE \& EFE, Analisa SWOT, Analytical Hirarchy Process (AHP), Business Model Canvas.

\section{Pendahuluan}

Bisnis merupakan suatu organisasi yang menyediakan barang atau jasa yang bertujuan untuk mendapatkan keuntungan [1]. Perkembangan bisnis dan industri di Indonesia semakin lama semakin meningkat persaingan. Keadaan ini menimbulkan persaingan antara perusahaan, pesaing yang semakin bertambah, volume produk yang semakin meningkat, bertambah pesatnya perkembangan teknologi. Hal ini menuntut perusahaan untuk lebih memerhatikan lingkungan [2].

Beberapa penelitian tentang pengembangan strategi telah banyak dilakukan. Umumnya metode yang digunakan dalam pengembangan strategi adalah menggunakan matriks Strength, Weakness, Opportunities, Threats (SWOT) dan bisnis model canvas. Menurut Aaker [3], Pengembangan strategi bisnis terdapat tiga tahap, yaitu tahap 
input, tahap pencocokan dan tahap pengambilan keputusan. Berbagai faktor internal dan eksternal yang diidentifikasi tersebut kemudian akan diberi pembobotan untuk dipetakan pada matriks Evaluasi Faktor Internal (Matriks IFE) dan Matriks Evaluasi Faktor Eksternal (Matriks EFE) sebagai tahap input. Hasil dari Matriks IE kemudian digunakan sebagai perumusan strategi alternatif yang dijabarkan matriks SWOT. Strategi alternatif yang telah dirumuskan kemudian diberi penilaian dan prioritas dengan Analitical Hirarchy Proses (AHP) bertujuan mengetahui prioritas strategi terbaik yang digunakan untuk tahap pengambilan keputusan. Penelitian yang dilakukan oleh Dewobroto [4], mengenai permasalahan Business Model Canvas membahas tentang perumusan bisnis model Business Model Canvas, dilakukan analisa cost structure atau proyeksi finansial untuk menentukan segmen dan target konsumen. Penelitian yang dilakukan oleh Aldianto and Gunawan [5] membahas tentang analisa problem dalam perusahaan dengan menggunakan 7Cs Compass Model Analysis yang dikombinasikan IFAS, EFAS dan Fishbone Diagram. Setijawibawa [6], dalam penelitiannya membahas mengenai evaluasi dan perancangan Business Model Canvas yang digabung dengan analisa SWOT. Hasil dari penelitian ini adalah dapat diketahui elemen model bisnis baru yang dapat dikembangkan lagi dalam perusahaan. Kosasi [7], dalam penelitiannya membahas tentang model bisnis dengan Business Model Canvas. Hasil yang didapatkan dari penelitian ini adalah menciptakan bisnis model baru dari pantai seafood restaurant yaitu pengembangan segmen pelanggan pada keluarga muda yang memiliki anak kecil dan lebih meningkatkan inovasi produk. Tjitradi [8], dalam penelitiannya membahas tentang merancang model bisnis berdasarkan kerangka Business Model Canvas. Hasil penelitian dari identifikasi Business Model Canvas ini menunjukkan gambaran mengenai elemen customer segment yang termasuk kedalam tipe segmented, berasal dari kalangan menengah ke atas.

Dari beberapa penelitian di atas terdapat kesamaan antara penelitian terdahulu dengan penelitian ini adalah keduanya menggunakan analisa Business Model Canvas. Di mana keseluruhan penelitian adalah mengembangkan bisnis model baru. Analisa yang dilakukan adalah analisa yang menggabungkan beberapa metode seperti analisa SWOT. Perbedaan penelitian ini dengan penelitian terdahulu adalah pada penelitian terdahulu hanya menggabungkan antara analisa Business Model Canvas dan SWOT. Namun pada penelitian ini juga menggunakan Analitical Hirarchy Proses (AHP) dan digabungkan dengan Business Model Canvas untuk menciptakan usulan pengembangan bisnis yang sesuai dengan prioritas kebutuhan strategi perusahaan. Perbedaan ini akan menghasilkan hasil yang berbeda dan metode ini akan lebih sesuai dengan kondisi pasar yang ada karena adanya perbedaan dalam proses pengambilan data. Diharapkan perusahaan dapat menyelesaikan permasalahan yang dihadapi sehingga perusahaan dapat tetap bertahan dan dapat meningkatkan penjualan agar diperoleh keuntungan yang maksimal, sehingga perusahaan dapat berkembang dengan cepat.

\section{Metode Penelitian}

Dalam penelitian ini pengumpulan data dilakukan dengan cara mengidentifikasi kekuatan, kelemahan, peluang dan ancaman perusahaan. Selanjutnya dilakukan pembobotan faktor internal dan faktor eksternal. Data diolah menggunakan matriks Internal factor Evaluation (IFE) dan Matriks external Factor Evaluation (EFE). Setelah diketahui skor disetiap masing - masing faktor pada matriks IFE dan matriks EFE maka akan diketahui weighted score. weighted score tersebut digunakan untuk melihat posisi dari perusahaan pada kuadran IE Matrix. 
Tahap selanjutnya menentukan posisi strategi dalam kuadran kartesius, apakah termasuk kuadran I, II, III, atau IV. Posisi strategi menentukan alternatif strategi yang diambil oleh perusahaan. Empat strategi utama yang dirumuskan yaitu, strategi SO (strength dan opportunities), strategi WO (weakness dan opportunities), strategi ST (strength dan treats) dan strategi WT (weakness dan treats). Tahap selanjutnya adalah menentukan prioritas strategi yang akan dijalankan perusahaan dengan menggunakan Analitical Hierarchy Prosess (AHP). Menurut Saaty [9], dalam menentukan prioritas harus diketahui hirarki keputusan. Setelah itu menyusun matriks perbandingan berpasangan (pairwise comparison). Matriks perbandingan berpasangan menggunakan skala 1 sampai dengan 9. Dari matriks perbandingan berpasangan, langkah selanjutnya yaitu membuat matriks prioritas dari masing masing alternatif strategi. Dilanjutkan dengan pencarian nilai dari bobot kriteria. Setelah itu dilakukan Uji Konsistensi dengan mencari CI (Consistency Index) dan dilanjutkan dengan mencari CR (Consistency Rasio). Berdasarkan strategi yang terpilih dilakukan pengembangan strategi sesuai dengan prioritas yang telah didapat dengan menggunakan Business Model Canvas.

Menurut Osterwalder and Pigneur [10], model bisnis menggambarkan dasar pemikiran tentang bagaimana organisasi menciptakan, memberikan, dan menangkap nilai Business Model Generation untuk mampu memberikan respons yang cepat terhadap keinginan pelanggan dengan memberikan nilai - nilai terbaik yang ada dalam perusahaan.

\section{Hasil dan Pembahasan}

\subsection{Analisa Faktor Internal dan Eksternal}

Hasil dari identifikasi faktor internal dan faktor eksternal serta hasil pembobotan yang telah didapatkan melalui penyebaran kuisioner kepada pihak perusahaan memberikan rangkuman kekuatan, kelemahan, peluang dan ancaman dalam matriks IFE dan EFE pada Tabel 1. Setelah melakukan pembobotan dengan IFE dan EFE, maka diketahui weighted score. weigthed score tersebut digunakan untuk melihat posisi dari UD. Cahaya pada kuadran IE Matrix serta untuk menentukan rekomendasi yang tepat untuk dijalankan oleh UD. Cahaya.

Dari Tabel 2 dapat disimpulkan bahwa UD. Cahaya berada pada kuadran (I) yaitu Grow \& build karena total skor yang didapatkan dari IFE sebesar 3.06 dan yang didapatkan dari EFE sebesar 3.422 total skor dari kedua faktor internal dan eksternal tergolong dalam kategori "Strong". Dengan demikian kondisi dari UD. Cahaya ini terbilang cukup baik dan dapat terus berkembang kedepannya. Dengan bertumpu pada matrix IFE dan EFE diharapkan UD. Cahaya dapat menutupi kelemahan yang ada dan fokus pada kekuatan serta peluang yang dimiliki. Sehingga akan bisa menghadapi ancaman yang ada.

\subsection{Analisa SWOT}

Matriks SWOT merupakan langkah - langkah berdasarkan pengembangan dari matriks IE. Berbagai alternatif strategi dapat dirumuskan berdasarkan model analisa SWOT, empat macam strategi utama yaitu strategi SO, ST, WO dan WT. Analisis ini menggunakan data yang diperoleh dari matriks EFE dan IFE diatas. Hasil analisa dilihat pada Tabel 3 keunggulan dari penggunaan model ini adalah mudah memformulasikan strategi berdasarkan gabungan faktor eksternal dan internal. 
Tabel 1 Perhitungan IFE dan EFE

\begin{tabular}{|c|c|c|c|}
\hline IFE & Nilai Bobot & Rating & Skor \\
\hline \multicolumn{4}{|l|}{ Indikator Kekuatan } \\
\hline Tersedianya bahan baku yang mudah didapat & 0,071 & 3 & 0,213 \\
\hline Pengolahan produk yang sederhana & 0,086 & 3,6 & 0,3096 \\
\hline Memiliki karyawan yang skill nya cukup baik dibidangnya & 0,086 & 3 & 0,258 \\
\hline Hasil Produk tidak menggunakan bahan kimia berbahaya & 0,086 & 4 & 0,344 \\
\hline Memiliki hasil produk yang berkualitas & 0,100 & 2,6 & 0,26 \\
\hline Produk sudah mulai dikenal oleh masyarakat & 0,114 & 3,6 & 0,4104 \\
\hline Total Skor Kekuatan & & & 1.795 \\
\hline \multicolumn{4}{|l|}{ Indikator Kelemahan } \\
\hline Belum memenuhi permintaan konsumen dengan tepat & 0,100 & 3,6 & 0,36 \\
\hline Kurangnya alat transportasi dan promosi produk & 0,071 & 3 & 0,213 \\
\hline Peralatan proses produksi sederhana & 0,071 & 2 & 0,142 \\
\hline Jangkauan pemasaran hanya mencakup daerah kota Malang & 0,057 & 2 & 0,114 \\
\hline Saluran pemasaran produk belum maksimal & 0,071 & 3 & 0,213 \\
\hline Kurangnya pengetahuan dan wawasan SDM & 0,086 & 2,6 & 0,2236 \\
\hline Total skor kelemahan & & & 1.265 \\
\hline Total keseluruhan IFE & & & 3.06 \\
\hline EFE & Nilai Bobot & Rating & Skor \\
\hline \multicolumn{4}{|l|}{ Indikator Peluang } \\
\hline Tingkat konsumsi masyarakat terhadap produk meningkat & 0,083 & 3 & 0,249 \\
\hline Banyaknya tempat wisata didalam kota maupun luar kota & 0,133 & 4 & 0,532 \\
\hline Banyaknya media promosi baik cetak maupun elektronik & 0,133 & 4 & 0,532 \\
\hline Potensi pasar cukup besar & 0,100 & 4 & 0,4 \\
\hline Permintaan konsumen terhadap makanan ringan tinggi & 0,100 & 3 & 0,3 \\
\hline Total skor peluang & & & 2.013 \\
\hline \multicolumn{4}{|l|}{ Indikator Ancaman } \\
\hline Masuknya pesaing baru & 0,100 & 3 & 0,3 \\
\hline Harga produk pesaing yang lebih murah & 0,133 & 2 & 0,266 \\
\hline Gencarnya promosi perusahaan pesaing & 0,133 & 2,6 & 0,3458 \\
\hline Banyaknya lokasi pemasaran produk pesaing & 0,083 & 3 & 0,249 \\
\hline Total skor ancaman & & & 1.397 \\
\hline Total keseluruan EFE & & & 3.422 \\
\hline
\end{tabular}


Tabel 2 Matriks Internal dan Eksternal (IE)

\begin{tabular}{|c|c|c|c|c|}
\hline \multicolumn{5}{|c|}{ IFE SCORE } \\
\hline \multirow{4}{*}{$\begin{array}{l}\text { EFE } \\
\text { SCORE }\end{array}$} & & $\begin{array}{lll}\text { Strong } & 3.0 \quad- \\
4.0 & & \end{array}$ & Average $2.0-2.99$ & Weak $1.0-1.99$ \\
\hline & High $3.0-4.0$ & $\begin{array}{l}\text { (I) grow and } \\
\text { build }\end{array}$ & $\begin{array}{l}\text { (II) grow and } \\
\text { build }\end{array}$ & $\begin{array}{l}\text { (III) hold and } \\
\text { maintain }\end{array}$ \\
\hline & $\begin{array}{l}\text { Medium } 2.0- \\
2.99\end{array}$ & $\begin{array}{l}\text { (IV) grow and } \\
\text { build }\end{array}$ & $\begin{array}{l}\text { (V) hold and } \\
\text { maintain }\end{array}$ & $\begin{array}{l}\text { (VI) harvest and } \\
\text { divest }\end{array}$ \\
\hline & Low $1.0-1.99$ & $\begin{array}{l}\text { (VI) hold and } \\
\text { maintain }\end{array}$ & $\begin{array}{l}\text { (VIII) harvest or } \\
\text { divest }\end{array}$ & $\begin{array}{l}\text { (XI) harvest or } \\
\text { divest }\end{array}$ \\
\hline
\end{tabular}

Tabel 3 Alternatif Strategi SWOT

\begin{tabular}{|c|c|c|}
\hline & Kekuatan (Strength) & Kelemahan (Weakness) \\
\hline \multirow[t]{2}{*}{$\begin{array}{l}\text { Peluang } \\
\text { (Opportunity) }\end{array}$} & Strategi S - O & Strategi W - O \\
\hline & $\begin{array}{l}\text { ST1. Meningkatkan pemasaran produk } \\
\text { melalui media cetak maupun } \\
\text { media elektronik (S2,S4,S5,O1,O4) } \\
\text { ST2. Melakukan penawaran produk dan } \\
\text { kerjasama dengan beberapa } \\
\text { penjual oleh -oleh wisata jawa } \\
\text { timur maupun luar jawa } \\
\text { (S4,S6,O2) } \\
\text { ST3. Menjamin dan meningkatkan } \\
\text { kualitas produk dan menambah } \\
\text { varian rasa } \\
\text { (S1,S2,S3,S4,O1,O4,O5) } \\
\text { ST4. Pengembangan pasar ke daerah } \\
\text { baru (S1,S4,S6,O4) } \\
\text { ST5. Memanfaatkan musim tertentu } \\
\text { untuk memenuhi permintaan } \\
\text { pasar (S3,S6,O5) }\end{array}$ & $\begin{array}{ll}\text { ST6. } & \text { Menambah jangkauan } \\
\text { pemasaran baik di } \\
\text { jawa timur maupun } \\
\text { luar jawa dan } \\
\text { menambah jumlah } \\
\text { produksi } \\
\text { (W1,W4,O1,O5) } \\
\text { ST7. } \\
\text { Mengadakan pelatihan } \\
\text { bagi karyawan agar } \\
\text { lebih terampil dan } \\
\text { kreatif (W6,O4) } \\
\text { ST8. Menambah alat } \\
\text { transportasi untuk } \\
\text { memperlancar } \\
\text { pengiriman barang } \\
\text { (W2,O2,O4) }\end{array}$ \\
\hline \multirow[t]{2}{*}{$\begin{array}{l}\text { Ancaman } \\
\text { (Threats) } \\
\end{array}$} & Strategi S - T & Strategi W - T \\
\hline & $\begin{array}{ll}\text { ST9. } & \text { Menjaga kualitas produk agar } \\
\text { lebih baik dan bersaing secara } \\
\text { kompetitif dalam harga } \\
(\mathrm{S} 1, \mathrm{~S} 2, \mathrm{~S} 3, \mathrm{~S} 4, \mathrm{~S} 5, \mathrm{~S} 6, \mathrm{~T} 1, \mathrm{~T} 2, \mathrm{~T} 4)\end{array}$ & $\begin{array}{l}\text { ST10. Meningkatkan produksi } \\
\text { dengan tepat guna } \\
\text { (W1,W3,T1,T4) }\end{array}$ \\
\hline
\end{tabular}

\subsection{Analytical Hierarchy Process (AHP)}

Perhitungan metode AHP digunakan untuk menentukan bobot kriteria dan subkriteria serta menentukan rasio konsistensi. Pada Tabel 4 dapat dilihat hasil akhir dari nilai prioritas strategi yang dikembangkan sesuai dengan peringkat. Dari Tabel 4 dapat disimpulkan bahwa strategi alternatif yang terpilih dengan bobot penilaian paling 
tinggi yaitu strategi pertama dengan nilai 0,22 dengan keterangan strategi yang harus diprioritaskan oleh perusahaan adalah "Meningkatkan pemasaran produk melalui media cetak maupun media elektronik (S2, S4, S5, O1, O4)".

Tabel 4 Bobot Prioritas Menyeluruh

\begin{tabular}{ccccccc}
\hline $\begin{array}{l}\text { Kriteria } \\
\text { Alternatif }\end{array}$ & S-O & W-O & S-T & W-T & $\begin{array}{l}\text { Prioritas } \\
\text { Menyeluruh }\end{array}$ & Prioritas \\
\hline Strategi 1 & 0,10 & 0,06 & 0,04 & 0,02 & 0,22 & 1 \\
Strategi 2 & 0,07 & 0,04 & 0,03 & 0,02 & 0,15 & 2 \\
Strategi 3 & 0,06 & 0,04 & 0,02 & 0,01 & 0,13 & 3 \\
Strategi 4 & 0,05 & 0,03 & 0,02 & 0,01 & 0,11 & 4 \\
Strategi 5 & 0,04 & 0,03 & 0,02 & 0,01 & 0,10 & 5 \\
Strategi 6 & 0,04 & 0,02 & 0,01 & 0,01 & 0,08 & 6 \\
Strategi 7 & 0,03 & 0,02 & 0,01 & 0,01 & 0,07 & 7 \\
Strategi 8 & 0,03 & 0,01 & 0,01 & 0,01 & 0,06 & 8 \\
Strategi 9 & 0,02 & 0,01 & 0,01 & 0,01 & 0,05 & 9 \\
Strategi 10 & 0,02 & 0,01 & 0,01 & 0,00 & 0,04 & 10 \\
\hline
\end{tabular}

\subsection{Pengembangan Business Model Canvas (BMC)}

Dari hasil analisa SWOT posisi UD. Cahaya berada pada posisi kuadran I yaitu strategi (strength dan Opportunities) yaitu menciptakan strategi yang menggunakan kekuatan untuk memanfaatkan peluang. Hasil AHP strategi alternatif yang terpilih dengan bobot penilaian paling tinggi yaitu strategi 1 dengan nilai 0,22 yaitu "Meningkatkan pemasaran produk melalui media cetak maupun media elektronik (S2,S4,S5,O1,O4)". Selanjutnya dilakukan pengembangan Business Model Canvas. Pada penyusunan pengembangan Business Model Canvas, UD. Cahaya memerlukan perbaikan model bisnis seperti terlihat pada Gambar 1.

Penggunaan matriks SWOT bertujuan untuk mempertajam analisis agar perusahaan dapat melihat posisi dan arah perkembangan. Strategi alternatif yang terpilih berdasarkan bobot penilaian paling tinggi harus diprioritaskan oleh perusahaan. Pengembangan lima blok bangunan dari kesembilan blok Business Model Canvas yang akan diterapkan pada UD. Cahaya seperti dibawah berikut;

1. Customer Relationship pada strategi 1 dengan nilai prioritas tertinggi dengan nilai 0,22 yaitu Meningkatkan pemasaran produk melalui media cetak maupun media elektronik (S2,S4,S5,O1,O4). Hubungan pelanggan dapat dibangun perusahaan melalui beberapa kategori mulai personal, maupun media. Strategi perusahaan untuk peningkatan penjualan adalah dengan melakukan promosi melalui media cetak seperti koran, majalah maupun brosur, website, blogger maupun media sosial seperti facebook, dan instagram.

2. Key Partners terdapat pada strategi 2 dengan nilai prioritas sebesar 0,15 yaitu menawarkan produk dan kerja sama dengan beberapa penjual di objek wisata jawa timur maupun luar jawa $(\mathrm{S} 4, \mathrm{~S} 6, \mathrm{O} 2)$. Untuk bisa meningkatkan pendapatan pada perusahaan harus terus melakukan promosi dan penawaran produk untuk mendapatkan customer baru seperti supermarket, toko oleh-oleh wisata baik di jawa timur maupun luar jawa. 
3. Value Propositions terdapat pada strategi 3 dengan nilai prioritas sebesar 0,13 yaitu Menjamin dan meningkatkan kualitas produk dan menambah varian rasa (S1,S2,S3,S4,O1,O4,O5). UD. Cahaya harus tetap meningkatkan kualitas produknya dan menjaga kepercayaan customer yang telah terjalin, tetapi UD. Cahaya juga harus tetap melakukan inovasi agar tidak tertinggal dengan para pesaing. UD. Cahaya dapat melakukan inovasi terhadap design kemasan produk yang terus dikembangkan dan varian rasa pada produk harus tetap ditambah.

4. Customer Segmen terdapat pada strategi 4 dengan nilai prioritas sebesar 0,11 yaitu Pengembangan pasar ke daerah baru (S1,S4,S6,O4). Pelanggan adalah partner yang memberikan keuntungan perusahaan. Perusahaan dapat memperoleh pelanggan baru melalui komunikasi dengan masyarakat jawa maupun luar jawa, mahasiswa, dan wisatawan.

5. Channel terdapat pada strategi 5 dengan prioritas sebesar 0,10 yaitu memanfaatkan musim tertentu untuk memenuhi permintaan pasar (S3,S6, O5). Saluran komunikasi, distribusi dan penjualan merupakan penghubung antara perusahaan dan pelanggan. Sebuah perusahaan dapat menjangkau pelanggan melalui reseller, kelompok organisasi, supermarket, dan pengguna aktif sosial media.

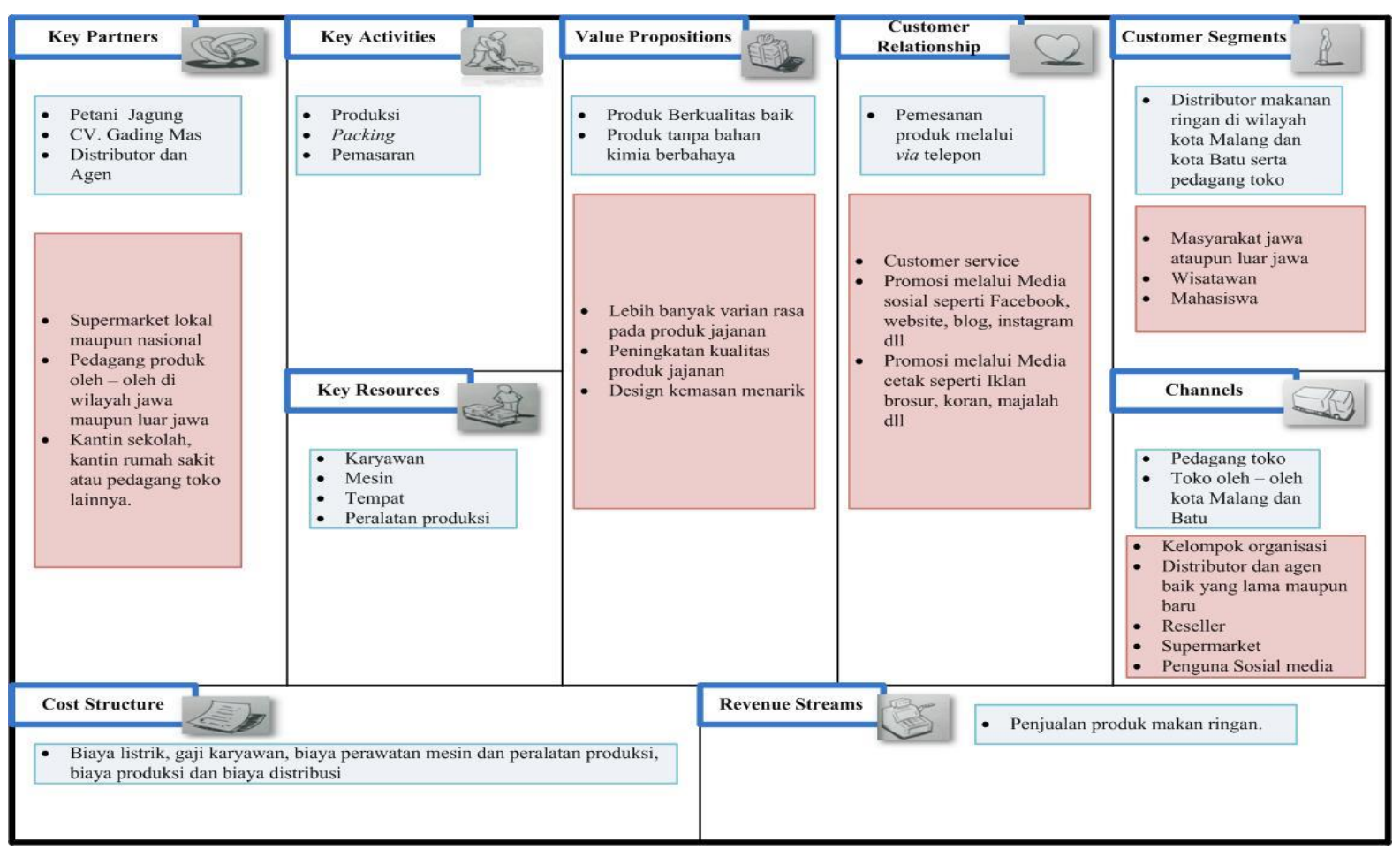

Gambar 1 Pengembangan Business Model Canvas pada UD. Cahaya

\section{Simpulan}

Hasil dari perhitungan pada faktor internal dan eksternal menunjukkan posisi UD. Cahaya saat ini berada pada kuadran I dengan nilai sebesar $(0,264 ; 0,307)$. serta analisa SWOT menghasilkan sepuluh alternatif strategi dengan prioritas strategi adalah meningkatkan pemasaran produk melalui media cetak maupun media elektronik dengan nilai bobot sebesar 0,22. Usulan prioritas perbaikan digunakan untuk meningkatkan proses bisnis perusahaan dapat dilakukan dengan mengaplikasikan konsep Business Model Canvas yang telah didapatkan dari perhitungan sebelumnya 
yaitu pada 5 blok bangunan Business Model Canvas di antaranya pada blok bangunan Customer Relationships (hubungan pelanggan), Key Patners (kemitraan utama), Value Propositions (proporsi nilai), Customer Segments (segmen pelanggan) dan Channel (saluran). Untuk penelitian selanjutnya sebaiknya melibatkan responden yang berasal dari lingkungan luar perusahaan yang tahu akan perusahaan dengan menggabunggan metode Business Model Canvas dengan value propotions design agar lebih mengetahui nilai pada perusahaan.

\section{Referensi}

[1] P. Kotler, Manajemen Pemasaran Analisis, Perencanaan, Implementasi dan Kontrol. Jakarta: Prenhallindo, 1997.

[2] M. E. Porter, Keunggulan Bersaing: menciptakan dan mempertahankan kinerja unggul: Penerbit Erlangga, 1992.

[3] D. A. Aaker, Manajemen Pemasaran Strategis. Salemba Empat: Jakarta, 2013.

[4] W. S. Dewobroto, "Penggunaan Business Model Canvas Sebagai Dasar Untuk Menciptakan Alternatif Strategi Bisnis dan Kelayakan Usaha," Jurnal Teknik Industri, vol. 1, pp. 215-230, 2013.

[5] L. Aldianto and M. F. Gunawan, "Box for Living Business Strategy 7Cs Compass Model Analysis and the Implementation of Business Model Canvas," Indonesian Journal of Business Administration, vol. 2, 2013.

[6] M. Setijawibawa, "Evaluasi Model Bisnis Pada Perusahaan X Menggunakan Business Model Canvas," Agora, vol. 3, pp. 305-313, 2015.

[7] V. M. Kosasi, "Analisis dan Evaluasi Model Bisnis pada Pantai Seafood Restaurant dengan Pendekatan Business Model Canvas," Agora, vol. 3, pp. 314323, 2015.

[8] E. C. Tjitradi, "Evaluasi Dan Perancangan Model Bisnis Berdasarkan Business Model Canvas," Agora, vol. 3, 2015.

[9] T. L. Saaty, Decision making with dependence and feedback: The analytic network process vol. 4922: RWS publications Pittsburgh, 1996.

[10] A. Osterwalder and Y. Pigneur, Business model generation: a handbook for visionaries, game changers, and challengers: John Wiley \& Sons, 2010. 